\title{
Abstract
}

\section{What anthropometric parameters and lipid parameters predict abnormal glucose tolerance in the first-degree relatives of patients with type 2 diabetes?}

Dahanayake $\mathrm{M}^{1^{*}}$, Rathnayake $\mathrm{M}^{1}$, Edirisinghe $\mathrm{U}^{1}$, Jayawardhana $\mathrm{M}^{1}$, Bethmiarachchi $\mathrm{D}^{1}$, Liyanage $\mathrm{G}^{1}$, Weerarathna $\mathrm{T}^{1}$

${ }^{1}$ Ministry of Health, Sri Lanka

\begin{abstract}
Introduction

First degree relatives of patients with type 2 diabetes have a high risk of pre-diabetes and diabetes. We aimed to study the predictors of abnormal glucose tolerance in this category.

Methods

Previously healthy 157 first degree relatives of type 2 diabetes were studied. Age was noted and body mass index (BMI) was calculated. All underwent 75 gram standard oral glucose tolerance test (OGTT) and fasting lipid profile. Association of each independent variable (age, gender, BMI, total cholesterol, low density lipoprotein, triglycerides, and high density lipoprotein level) with impaired glucose tolerance (IGT) was studied with binary logistic regression as the 2 hour value of OGTT $140 \mathrm{mg} / \mathrm{dL}$ as the dependent variable.

Results

Majority (63\%) of the sample were females. Mean (SD) age, and BMI were 49.9(11) years and 23.5(3.6) $\mathrm{kg} / \mathrm{m}^{2}$ respectively. 26/ 157 had IGT and 22 had diabetes on OGTT. Binary logistic regression revealed age and BMI as significant risk factors $(\operatorname{Exp}>1$ with $\mathrm{p}<0.05)$ and total cholesterol and triglycerides as associations $(\operatorname{Exp}>1$ with $p$ $>0.05)$ of IGT.

Conclusions

First degree relatives of type 2 diabetic patients with higher BMI and age are at increased risk of developing prediabetes and diabetes. Early screening to uncover abnormal glucose tolerance in this subcategory of individuals is
\end{abstract}

Key words: Type2 Diabetes mellitus; Impaired Glucose Tolerance; Predictors

Copyright: (C) 2015 Dahanayake M et al. This is an open access article distributed under the Creative Commons Attribution License, which permits unrestricted use, distribution, and reproduction in any medium, provided the original work is properly cited.

* Correspondence : dahanayakemalin@yahoo.com

Cite this abstract as: Dahanayake M, Rathnayake M, Edirisinghe U, Jayawardhana M, Bethmiarachchi D, Liyanage $\mathrm{G}$, Weerarathna T. What anthropometric parameters and lipid parameters predict abnormal glucose tolerance in the first-degree relatives of patients with type 2 diabetes?. Anuradhapura Medical Journal 2015;9 (2Supp):S15.

DOI: http://dx.doi.org/10.4038/ amj.v9i2Supp.7564 


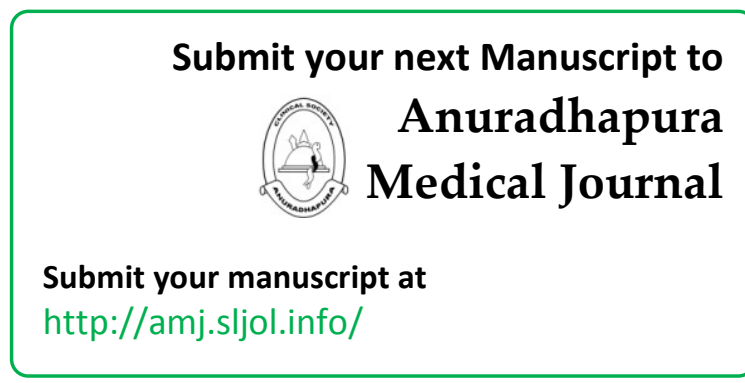

